\title{
Cerebral embolism and mitral stenosis : survival with and without anticoagulants
}

\author{
G. F. ADAMS, J. D. MERRETT, W. M. HUTCHINSON, \\ AND A. M. POLLOCK \\ From the Queen's University and Wakehurst House, City Hospital, Belfast
}

SYNOPSIS Eighty-four patients with mitral stenosis and cerebral embolism have been followed up for 20 years. Half of the series (those treated in the early years) had no anticoagulant treatment and half were given long-term warfarin therapy. Mortality rate and causes of death have been reviewed, and comparison of survival times of treated and untreated groups by life-table analysis bears out the immediate need for anticoagulants when a diagnosis of systemic embolism is established. It is wise to continue the treatment for six months but it may be reasonable to discontinue it after one year with patients who can be assured of regular review.

Cerebral embolism complicating mitral stenosis represents less than $10 \%$ of patients with strokes admitted as emergencies to general hospital wards (Carter, 1957; Groch et al., 1961; Adams, 1965 ), and only $5 \%$ of 2,180 patients referred for stroke rehabilitation to this department in 20 years.

As rheumatic heart disease declines in frequency and cardiac surgery extends its scope the incidence of systemic embolism complicating mitral stenosis is likely to be reduced. Meanwhile, however, there must still be many rheumatic patients on anticoagulant therapy, the only alternative for those unsuitable or unfit for operation. There is uncertainty about the value and the duration of anticoagulant treatment for these patients, so that it was considered worthwhile to investigate the period of survival in a group kept under review since 1949, of whom half received anticoagulant therapy and half did not.

\section{ANALYSIS OF CASES}

The series comprises 109 patients with mitral valve disease and atrial fibrillation who survived the onset of cerebral embolism and about two weeks later were transferred from admission wards to a stroke rehabilitation unit. All had severe or moderately severe hemiplegia, and the series does not include immediate deaths, or patients with minor transient episodes.

Twenty-five were rejected after review. These comprised:

1. Sixteen valvotomy patients, either because the hemiplegia was postoperative, or because the operation would obviously have affected mortality.

2. Six, all over 60 years of age, because reexamination of the history suggested that the infarct was non-embolic.

3. Two younger patients, because hypertension and atheroma seemed more likely aetiological factors than rheumatic heart disease.

4. One patient with little residual motor deficit who died, with dementia, six months after onset.

Of the remaining 84 patients, only three were in

\section{TABLE 1}

CEREBRAL EMBOLISM AND MITRAL STENOSIS: SURVIVAL WITH AND WITHOUT ANTICOAGULANTS; DURATION OF THERAPY IN PATIENTS WHOSE ANTICOAGULANT CONTROL WAS 'POOR'

\begin{tabular}{cc}
\hline Time & Number \\
\hline$<1$ month & - \\
$1-3$ months & 9 \\
$4-12$ months & 5 \\
$1-2$ years & 4 \\
3 years + & 1 \\
\hline Total & 19 \\
\hline
\end{tabular}


sinus rhythm on admission to hospital with their strokes, and all later developed atrial fibrillation.

Half of these patients (10 males and 32 females) were not given anticoagulants, and the remainder (13 males and 29 females) were treated, some in the early years, with phenindione, but all eventually with warfarin sodium.

Treatment for all but three began within two weeks of onset of the cerebral episode, aiming at thrombotest levels (Owren, 1959) between 12 and 20\%. Anticoagulant control was considered 'good' if treatment was constant throughout the follow-up period, with thrombotest percentages consistently below $30 \%$ at the monthly review clinic. Control was 'poor' if discontinued either by default, or because thrombotest levels were persistently unsatisfactory or unsafe. However, some of the 19 patients in this poor control group continued treatment for three years or more (Table 1).

No deliberate dividing line was drawn between treated and untreated groups. It happened as anticoagulant therapy came to be used in rheumatic heart disease, and the two groups represent two decades-1949-59 without, and 1959-69 with treatment.

Most of the data for this investigation were available from a card-index of all stroke patients treated and reviewed annually in the department. Records include age at onset, sex, functional cardiac capacity (New York Heart Association Grade, 1964), cardiac rhythm at onset, associated valve disease, anticoagulant control, stroke recovery grade (Adams and Merrett, 1961), and survival and cause of death.

\section{RESULTS}

We have compared survival times, mortality rates and causes of death in treated and untreated groups, and in those with good or poor anticoagulant control.

There are no significant differences $(\mathrm{P}<0.05$ applied throughout) between the two groups in respect of age, sex, or cardiac grade (Table 2), and there have been no changes in arrangements for admission or treatment of these patients which would account for differences in other respects apart from the use of anticoagulants.

STATISTICAL ANALYSIS Only one member of the untreated group survives-apparently an example of the benign course of established rheumatic heart disease experienced by some old people (Bedford and Caird, 1960). Sixteen of the
TABLE 2

COMPARISON OF UNTREATED PATIENTS AND THOSE TREATED WITH ANTICOAGULANTS

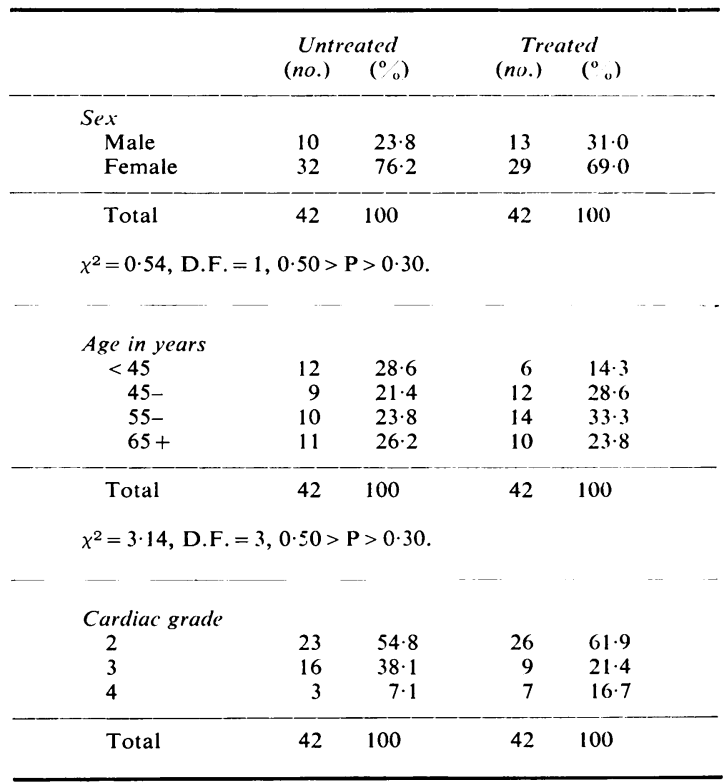

$\chi^{2}=3 \cdot 74$, D.F. $=2,0 \cdot 20>\mathrm{P}>0 \cdot 10$.

TABLE 3

PERCENTAGE NUMBERS OF UNTREATED AND TREATED GROUPS SURVIVING

\begin{tabular}{cccc}
\hline $\begin{array}{c}\text { Survival } \\
\text { in years to }\end{array}$ & Untreated & Treated & Treated-untreated \\
\hline 0 & & & \\
\hline$\frac{1}{2}$ & 100 & 100 & \\
1 & $76 \cdot 2$ & 100 & $23 \cdot 8^{*} \pm-$ \\
$1 \frac{1}{2}$ & $73 \cdot 8$ & $90 \cdot 5$ & $16 \cdot 7^{*} \pm 8 \cdot 16$ \\
2 & $66 \cdot 7$ & $88 \cdot 1$ & $21 \cdot 4^{*} \pm 8 \cdot 83$ \\
$2 \frac{1}{2}$ & $59 \cdot 5$ & $88 \cdot 1$ & $28 \cdot 6^{*} \pm 9 \cdot 07$ \\
3 & $54 \cdot 8$ & $76 \cdot 0$ & $21 \cdot 2^{*} \pm 10 \cdot 13$ \\
$3 \frac{1}{2}$ & $42 \cdot 9$ & $65 \cdot 7$ & $22 \cdot 8^{*} \pm 10 \cdot 67$ \\
4 & $40 \cdot 5$ & $57 \cdot 3$ & $16 \cdot 8 \pm 10 \cdot 96$ \\
$4 \frac{1}{2}$ & $35 \cdot 7$ & $51 \cdot 6$ & $15 \cdot 9 \pm 10 \cdot 97$ \\
5 & $31 \cdot 0$ & $48 \cdot 6$ & $17 \cdot 6 \pm 10 \cdot 84$ \\
$5 \frac{1}{2}$ & $28 \cdot 6$ & $45 \cdot 5$ & $16 \cdot 9 \pm 10 \cdot 77$ \\
6 & $28 \cdot 6$ & $42 \cdot 3$ & $13 \cdot 7 \pm 10 \cdot 80$ \\
$6 \frac{1}{2}$ & $28 \cdot 6$ & $38 \cdot 7$ & $10 \cdot 1 \pm 10 \cdot 82$ \\
7 & $28 \cdot 6$ & $38 \cdot 7$ & $10 \cdot 1 \pm 10 \cdot 82$ \\
$7 \frac{1}{2}$ & $26 \cdot 2$ & $38 \cdot 7$ & $12 \cdot 5 \pm 10 \cdot 70$ \\
8 & $19 \cdot 0$ & $38 \cdot 7$ & $19 \cdot 7 \pm 10 \cdot 25$ \\
$8 \frac{1}{2}$ & $16 \cdot 7$ & $38 \cdot 7$ & $22 \cdot 0^{*} \pm 10 \cdot 08$ \\
9 & $16 \cdot 7$ & $38 \cdot 7$ & $22 \cdot 0^{*} \pm 10 \cdot 08$ \\
$9 \frac{1}{2}$ & $16 \cdot 7$ & $38 \cdot 7$ & $22 \cdot 0^{*} \pm 10 \cdot 08$ \\
10 & $11 \cdot 9$ & $31 \cdot 0$ & $19 \cdot 1 \pm 10 \cdot 81$ \\
& $7 \cdot 1$ & $31 \cdot 0$ & $23 \cdot 9 * \pm 10 \cdot 38$ \\
\hline & & & \\
\hline
\end{tabular}

* Significant at $\mathrm{P}<0.05$ 


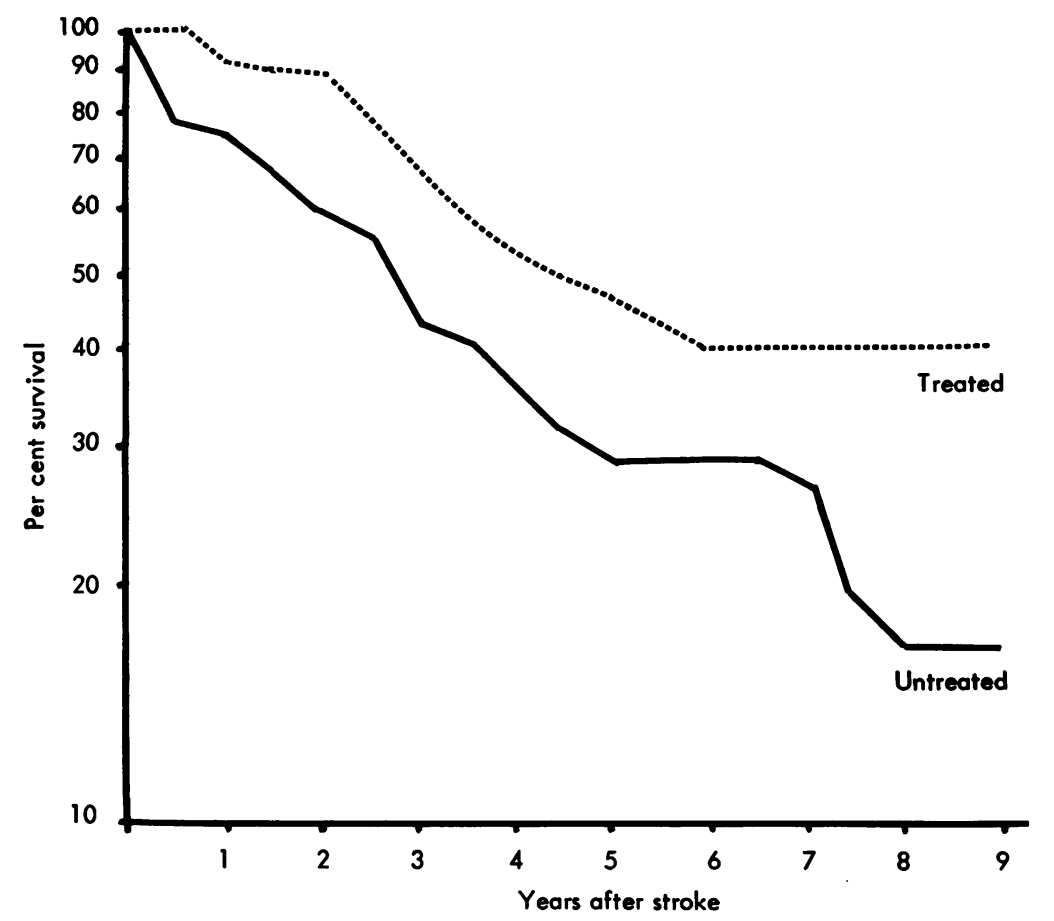

FIGURE Survival after cerebral embolism complicating mitral stenosis. Comparison of groups treated with, and without, anticoagulants.

treated group are still alive, so that survival has to be compared by life-table analysis (Berkson and Gage, 1950). The curves in logarithmic scale in the Figure show that the proportion of treated patients surviving for any given time is greater than the corresponding proportion in the untreated group. Differences were significant $(\mathrm{P}<0.05)$ at six months, one, one-and-a-half, two, two-and-a-half, three, eight, eight-and-ahalf, nine, and 10 years. Because one of the percentages is 100 the significance of this difference cannot be assessed by the technique used for the other differences in Table 3. An alternative technique (exact probability test) confirms a significant difference (at six months) between the two groups $(P=0.0011)$.

The essential difference between the curves is brought about by the higher mortality in the untreated group in the first six months after onset of embolism. After this interval the curves run parallel, mortality evidently being about the same in untreated as in treated patients. Differences reappear at seven years, but by then numbers are too small for reliable comparisons. Apparently, therefore, anticoagulant treat- ment reduces mortality in the first six months after a cerebral embolism complicating mitral stenosis, but does not seem to affect life expec-? tancy thereafter.

CAUSES OF DEATH In a review of hospital records and Registrar General's returns, congestive heart failure was the outstanding cause of death recorded, accounting for 41 patients about equally divided between the two groups (Table 4). Among the patients treated with anticoagulants, 10 (on good cover) and nine (on poor cover) died of congestive failure.

Recurrent embolism was thought to have caused 13 deaths in the untreated group, but in four of these the patients died at home some years after the original strokes and the episodes were regarded as embolic because the onset was said to have been 'sudden'. Five of the remaining nine hospital deaths occurred within the first three months after onset, and in three of these embolism was confirmed at necropsy.

In contrast, there have been only four embolic deaths among the treated patients so far, none within the first nine months after onset. Two 
TABLE 4

MORTALITY AND CAUSE OF DEATH

\begin{tabular}{lccc}
\hline \multirow{2}{*}{ Cause of death } & \multicolumn{2}{c}{ Deaths } & \multirow{2}{*}{ Total } \\
\cline { 2 - 4 } & Untreated & Treated & \\
\hline Congestive heart failure & 22 & 19 & 41 \\
Recurrence of embolism & 13 & 4 & 17 \\
Pneumonia and other & 6 & 3 & 9 \\
\hline Total died & 41 & 26 & 67 \\
Still living & 1 & 16 & 17 \\
\hline Total & 42 & 42 & 84 \\
\hline
\end{tabular}

have died on good anticoagulant control at twoand-a-half and four-and-a-half years, one with pulmonary and the other with femoral embolism, and two on poor control have died at nine months and three years with aortic saddle-emboli confirmed at necropsy.

It seems unlikely that half of the 16 survivors of the treated group will die of embolism to match the proportion of recurrences in the untreated group. Five of these survivors have been without anticoagulants for one reason or another for two years or more without incident. The evidence, such as it is, underlines the value of immediate effective anticoagulation in mitral stenosis with systemic embolism, but also emphasizes its relative uselessness as long-term treatment if surgical relief of valve disease cannot be attempted.

GRADES OF RECOVERY Among patients with non-embolic cerebral infarction who recover from their strokes, about $45 \%$ make grade I recoveries, becoming fully independent, able to walk with confidence, with some use of the affected hand, and normal intellect, and $55 \%$ become grade II, being more handicapped, with loss of a rhythmical walk, paresis of the arm, and perhaps intellectual impairment (Adams and Merrett, 1961).

When the 62 patients with recovery in this series were similarly graded, $66 \%$ were in grade II, and this significantly higher proportion in grade II was conspicuous in the treated group, perhaps because of diminished numbers of immediate and early deaths in the first six months.
It may seem strange to suggest that severe and long-lasting disability occurs less often after nonembolic cerebral infarcts than with cerebral embolism in rheumatic heart disease. Younger cardiac invalids might be expected to have a better collateral circulation than older patients with atheromatous cerebral arteries. A possible explanation is that widespread persistent vasoconstriction may be induced by embolism in the healthy vessels of younger individuals (Villarel and Cachera, 1939), which would prolong the ischaemia around the infarct and augment the cerebral damage. However, our experience supports an optimistic long-term outlook for neurological recovery in many of these patients (Keen and Leveaux, 1958), especially when a continuous programme of rehabilitation is followed for two years or more.

\section{DISCUSSION}

Sudden cerebral embolism often kills or cripples patients with mitral stenosis who are otherwise free of symptoms and in a fair state of cardiac compensation (Harris and Levine, 1941; British Medical Journal, 1964). The principal predisposing factors are advancing age and the rising incidence of atrial fibrillation associated with it (Askey and Cherry, 1950; Cosgriff, 1950; British Medical Journal, 1964; Carter, 1965; Coulshed et al., 1970; Fleming and Bailey, 1971).

At ages less than 35 years the incidence of systemic embolism is as low as $4.4 \%$ rising to $31.6 \%$ over 36 years of age (Coulshed et al., 1970).

Experience with a total of 172 patients reviewed by Keen and Leveaux (1958) showed an incidence of cerebral embolism of $20 \%$ but, in a much larger series (754 patients), Szekely (1964) found the overall incidence to be $9.6 \%$, onethird of emboli occurring within one month and two-thirds within a year of the onset of atrial fibrillation. Most authors confirm this high incidence of embolism in the first year after fibrillation appears, but Wells (1959) observed that $47 \%$ of emboli occurred in patients with sinus rhythm in his series, and Fleming and Bailey (1971) recorded $11 \%$, noting that the rate of embolism in sinus rhythm is unusually high in young women. However, just how often paroxysmal fibrillation is responsible for embolism in 
those regarded as having normal rhythm is unknown (Wood, 1954).

Estimates of the proportion of embolic episodes in rheumatic heart disease which are cerebral vary from $75 \%$ (Wood, 1954) to less than $25 \%$ (Jordan et al., 1951). McDevitt (1961) considers the proportion to be 'more than a third'. About one in six original systemic emboli proves fatal (Askey and Bernstein, 1960). All are agreed that cerebral embolism is a particularly serious complication. Daley et al. (1951) concluded that approximately $50 \%$ of all emboli were cerebral, with almost a 50\% mortality within a year of onset. Harris and Levine (1941) reported an immediate mortality of $33 \%$ in their series of patients with cerebral emboli, and an added percentage recorded as having died with an average survival time of 13 months, would bring this proportion nearer to the $54 \%$ of deaths within 12 months reported by Carter (1965).

Apart from the high mortality, residual motor disability after cerebral embolism is usually severe with a high risk of further embolism in the early weeks or months after the first episode (Wells, 1961; Fleming and Bailey, 1971).

In some patients the predominant symptoms may be neuropsychiatric (Towbin, 1955). The patient ' $d$ ' in our rejections may well have been one of these. Although it is difficult to anticipate the onset of embolism, Wood (1954) believed that prophylaxis of further episodes might be possible in $60 \%$ of patients and the outlook is so often so poor that immediate preventive treatment is essential. The alternatives are surgery or anticoagulants.

Some authors have recommended immediate surgery, if only to tie off the atrial appendage (British Medical Journal, 1964; Sommerville and Chambers, 1964). Others have found that systemic embolism is as common with small as with large appendages, and that removal of the appendage does not always protect against postoperative embolism (Szekely, 1964; Coulshed et al., 1970). The value of anticoagulant therapy is strongly advocated (Askey and Cherry, 1950; Cosgriff, 1950, 1953; Wood and Conn, 1954; Carter, 1957, 1965; Wells, 1959; Owren, 1963; Casella et al., 1964; Szekely, 1964; Marshall, 1966; Coulshed et al., 1970; Fleming and Bailey, 1971), but there is considerable doubt as to how soon it should be instituted, in view of the risk of haemorrhage, and how long it should be continued.

Owren (1959) believed that all patients with mitral valvular disease who have experienced embolism should be on life-long anticoagulant prophylaxis. Szekely (1964) suggested continuous treatment for a year, the period of greatest risk after the onset of fibrillation or embolism, but observed that some patients (unspecified) may require a longer course.

Carter (1965) claimed that treatment with anticoagulants significantly improved the prognosis of cerebral embolism in relation to immediate outcome, late survival, and recurrence, and suggested that duration of treatment may be determined by the underlying cardiac condition, varying from a year in cardiac infarction to two years in mitral stenosis.

However, in our patients embolism was attributable to rheumatic heart disease only, whereas Carter included among his 130 patients 43 with cardiac infarction and others with $\infty$ cerebral emboli associated with ischaemic heart응 응 disease, bacterial endocarditis, and thyrotoxico sis. The recurrence rate remained high for $\operatorname{six} 8 \frac{7}{0}$ months after embolism associated with cardiaa infarction, but all danger of recurrence seemedo to disappear after a year. In mitral stenosis with. persistent fibrillation the risk of recurrence was high for two years after embolism and this was the period of anticoagulant therapy he recommended.

Fleming and Bailey (1971) strongly recommended long-term treatment with anticoagulants and their exceptional results support this view. They reported only five further embolic episodes in 217 patients with mitral stenosis complicated by embolism treated over a period of nine-and-ahalf years, a rate of only $0.8 \%$ per patienttreatment-year.

The outpatient attendance and blood-sampling necessary to control long-term anticoagulant therapy becomes an unremitting chore, and patients on this treatment have complained of a loss of their sense of well-being. If the difference in mortality between our two groups of patients in the first six months of treatment is the result of the anticoagulant therapy (and we can see no other explanation), then it is possible that a limited period of anticoagulant control may be 
adequate rather than life-long prophylaxis. Treatment should begin immediately a diagnosis of systemic embolism is made, should continue for at least six months, but might be discontinued after a year.

Apart from the obvious benefits of progress in cardiac surgery in forestalling re-stenosis and congestive failure, perhaps the greatest advance on behalf of these patients would be the detection of atrial thrombosis in its earliest stages so that the possibility of systemic embolism might not only be predicted but also prevented.

We are most grateful to many of our colleagues who referred the patients included in this study, to Professor Florence McKeown and Professor J. E. Morison for their advice, and to Mrs. Vera Stewart for the preparation of the manuscript and Tables.

\section{REFERENCES}

Adams, G. F., and Merrett, J. D. (1961). Prognosis and survival after strokes. British Medical Journal, 1, 309-314.

Adams, G. F. (1965). Prospects for patients with strokes, with special reference to the hypertensive hemiplegic. British Medical Journal, 2, 253-259.

Askey, J. M., and Cherry, C. B. (1950). Thromboembolism associated with auricular fibrillation. Journal of the American Medical Association, 144, 97-100.

Askey, J. M., and Bernstein, S. (1960). The management of rheumatic heart disease in relation to systemic arterial embolism. Progress in Cardiovascular Diseases, 3, 220-232.

Bedford, P. D., and Caird, F. I. (1960). Valvular Disease of the Heart in Old Age, p. 53. Churchill: London.

Berkson, J., and Gage, R. P. (1950). Calculation of survival rates for cancer. Proceedings of the Staff Meetings of the Mayo Clinic, 25, 270-286.

British Medical Journal (1964). Embolism in mitral valve disease. 2, 1149-1150.

Carter, A. B. (1957). The immediate treatment of cerebral embolism. Quarterly Journal of Medicine, 26, 335-347.

Carter, A. B. (1965). Prognosis of cerebral embolism. Lancet, 2, 514-519.

Casella, L., Abelmann, W. H., and Ellis, L. B. (1964). Patients with mitral stenosis and systemic emboli. Archives of Internal Medicine, 114, 773-781.

Cosgriff, S. W. (1950). Prophylaxis of recurrent embolism of intracardiac origin. Journal of the American Medical Association, 143, 870-872.

Cosgriff, S. W. (1953). Chronic anticoagulant therapy in recurrent embolism of cardiac origin. Annals of Internal Medicine, 38, 278-287.

Coulshed, N., Epstein, E. J., McKendrick, C. S., Galloway, R. W., and Walker, E. (1970). Systemic embolism in mitral valve disease. British Heart Journal, 32, 26-34.

Daley, R., Mattingly, T. W., Holt, C. L., Bland, E. F., and . White, P. D. (1951). Systemic arterial embolism in rheumatic heart disease. American Heart Journal, 42, 566-581.

Fleming, H. A., and Bailey, S. M. (1971). Mitral valve disease, systemic embolism and anticoagulants. Postgraduate Medical Journal, 47, 599-604.

Groch, S. N., McDevitt, E., and Wright, I. S. (1961). A longterm study of cerebral vascular disease. Annals of Internal Medicine, 55, 358-367.

Harris, A. W., and Levine, S. A. (1941). Cerebral embolism in mitral stenosis. Annals of Internal Medicine, 15, 637-643.

Jordan, R. A., Scheifley, C. H., and Edwards, J. E. (1951). Mural thrombosis and arterial embolism in mitral stenosis. Circulation, 3, 363-367.

Keen, G., and Leveaux, V. M. (1958). Prognosis of cerebral embolism in rheumatic heart disease. British Medical Journal, 2, 91-92.

Marshall, J. (1966). The prevention of strokes. American Heart Journal, 71, 1-4.

McDevitt, E. (1961). Anticoagulant therapy in patients with rheumatic heart disease. In Cerebral Vascular Diseases, pp. 90-93 and 100-105. Edited by C. H. Millikan, R. G. Siekert, and J. P. Whisnant. Grune and Stratton: New York.

New York Heart Association (1964). Diseases of the Heart and Blood Vessels. 6th edn., p. 112. Little, Brown: Boston.

Owren, P. A. (1959). Thrombotest. A new method for controlling anticoagulant therapy. Lancet, 2, 754-758.

Owren, P. A. (1963). The results of anticoagulant therapy in Norway. Archives of Internal Medicine, 111, 240-247.

Somerville, W., and Chambers, R. J. (1964). Systemic embolism in mitral stenosis. British Medical Journal, 2, $1167-1169$.

Szekely, P. (1964). Systemic embolism and anticoagulant prophylaxis in rheumatic heart disease. British Medical Journal, 1, 1209-1212.

Towbin, A. (1955). Recurrent cerebral embolism. Archives of Neurology and Psychiatry, 73, 173-192.

Villarel, M., and Cachera, R. (1939). Les Embolies Cerebrales. Masson: Paris.

Wells, C. E. (1959). Cerebral embolism. The natural history, prognostic signs, and effects of anticoagulation. Archives of Neurology and Psychiatry, 81, 667-677.

Wells, C. E. (1961). Anticipation of emboli. In Cerebral Vascular Diseases, pp. 82-85. Edited by C. H. Millikan, R. G. Siekert, and J. P. Whisnant. Grune and Stratton, New York.

Wood, J. C., and Conn, H. L., Jr. (1954). Prevention of systemic arterial embolism in chronic rheumatic heart disease by means of protracted anticoagulant therapy. Circulation, 10, 517-523.

Wood, P. (1954). An appreciation of mitral stenosis. Part 1. Clinical features. British Medical Journal, 1, 1051-1063. 